\title{
Assessment of Knowledge, Attitudes, and Practices Regarding Chronic Hepatitis C Treatment and Its Challenges: A Survey of Internal Medicine Residents in a Community Hospital
}

\author{
Mazin Khalid ${ }^{\mathrm{a}, \mathrm{d}}$, Sumit Dahala, Vijay Gayam ${ }^{\mathrm{a}}$, Amrendra Mandal ${ }^{\mathrm{a}}$, Muhammad R. Hossain ${ }^{\mathrm{a}}$, \\ Osama Mukhtar ${ }^{\mathrm{a}}$, Mowyad Khalid ${ }^{\mathrm{b}}$, Pavani Garlapati ${ }^{\mathrm{a}}$, Mohammed Mansour ${ }^{\mathrm{c}}$
}

\begin{abstract}
Background: Despite recent advances in chronic hepatitis C (CHC) treatment, only a small proportion of patients are connected with care and receive treatment. Internal medicine (IM) residents spend nearly one-third of their training in primary care settings and play a crucial role in diagnosing and counseling patients as well as linking patients with care and following up.
\end{abstract}

Methods: IM residents in a community hospital completed an anonymous questionnaire regarding their knowledge, attitude, and practice associated with $\mathrm{CHC}$ treatment and its challenges.

Results: Descriptive analysis of the survey showed that there is a substantial gap in knowledge regarding the newer treatment of $\mathrm{CHC}$ between IM residents' perceptions of patient awareness and IM residents.

Conclusion: Updated education regarding $\mathrm{CHC}$ that is geared towards medical residents and focused on new modalities of treatment can narrow the gap and lead to considerable increases in the rates of diagnosis and treatment and decreases in morbidity and mortality.

Keywords: Chronic hepatitis C; Internal medical; Resident; Patient; Barrier; Knowledge; Practice; Attitude

\section{Introduction}

An estimated 2.7 - 3.9 million people in the United States

Manuscript submitted January 8, 2018, accepted February 8, 2018

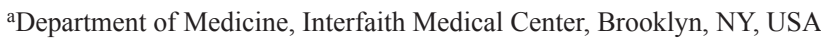

bepartment of Medicine, Detroit Medical Center, Wayne State University, Detroit, MI, USA

'Department of Gastroenterology, Interfaith Medical Center, Brooklyn, NY, USA

${ }^{\mathrm{d} C o r r e s p o n d i n g ~ A u t h o r: ~ M a z i n ~ K h a l i d, ~ D e p a r t m e n t ~ o f ~ M e d i c i n e, ~ I n t e r f a i t h ~}$ Medical Center, Brooklyn, NY 11213, USA.

Email: Dr.mazinkhalid@gmail.com

doi: https://doi.org/10.14740/gr963w
(US) have chronic hepatitis $\mathrm{C}(\mathrm{CHC})[1,2]$. Among those with $\mathrm{CHC}$, an estimated $38 \%$ are given referrals to see specialists, $11 \%$ received treatment and only $6 \%$ were cured [3]. The deficiency in the linkage to care and treatment rate has been attributed to patient perception of tolerability, the asymptomatic nature of the initial phase of the disease, fear of side effects associated with medications, limited access to specialists, and the expensive price of medications [4-7].

Resident physicians play an important role in health care delivery in the US. A total of 26,381 resident physicians were rotating in internal medicine in the academic year of 2015 2016 [8]. Residents are required to spend one-third of their training in an ambulatory care setting encountering patients [9]. While previous studies have attempted to understand the barriers to $\mathrm{CHC}$ treatment from the perspective of primary care providers, no study has assessed the knowledge, attitudes, practices, and perceptions of resident physicians regarding $\mathrm{CHC}$ treatment and its barriers.

\section{Methodology}

Resident physicians in their first, second, and third year of training in internal medicine in an academic community hospital were asked to complete an anonymous online questionnaire regarding their knowledge, attitudes, and practices associated with $\mathrm{CHC}$ and its treatment. The questionnaire also included their perception of barriers to $\mathrm{CHC}$ treatment. The residents were asked to complete the questionnaire based on their existing knowledge and practice without the use of any additional resources to influence their answers. A descriptive analysis of the results was conducted and presented as percentages.

\section{Results}

A total of 83 residents completed the survey. In our study, 57\% of the participants were males, and of these, $77 \%$ were from Asian descent, $6 \%$ were white, $3 \%$ were black, and $12 \%$ identified their ethnicity as other.

The number of patients seen in the last year by the medical residents is shown in Table 1. The majority of them (51\%) 
Table 1. Number of Patients With Hepatitis C Viral Infection Seen in the Past Year

\begin{tabular}{lll} 
& $\mathbf{n}$ & $\mathbf{\%}$ \\
\hline$<10$ & 30 & 36.14 \\
$10-50$ & 43 & 51.81 \\
$51-100$ & 9 & 10.84 \\
$>100$ & 1 & 1.20 \\
\hline
\end{tabular}

reported interacting with 10 to 50 patients with $\mathrm{CHC}$.

Only $43 \%$ of residents ordered hepatitis $\mathrm{C}$ screening for patients between 15 and 65 years of age, and 77\% screened individuals born between 1945 and 1965 (i.e., Baby Boomers). In contrast, $90.3 \%$ of the screened patients had histories of IV drug abuse, and $90 \%$ of the screened patients had histories of human immunodeficiency virus (HIV), as shown in Table 2.

Of the 83 participants, 66 residents $(79 \%)$ knew that $\mathrm{CHC}$ is curable, while $15(18 \%)$ thought it was only curable in certain conditions, as shown in Table 3.

Eighty percent of the residents were aware that there is treatment for $\mathrm{CHC}$ in the setting of co-infection with HIV. Nearly two-thirds of the residents knew that there are treatment modalities available for chronic kidney disease (CKD), liver cirrhosis, and depression, while only one-third knew that decompensated liver disease can be treated, as shown in Table 4. Ninety percent of the residents were aware of the impact of genotype on treatment selection and duration. Interestingly, more than one-third of the participants believed that patients with $\mathrm{CHC}$ who fail to respond to the initial treatment might require maintenance treatment.

With respect to practice, $78 \%$ of the participants reported ordering hepatitis A and hepatitis B titers in every patient with $\mathrm{CHC}$; the rest of the residents reported ordering the test often or most of the time. Similarly, $84 \%$ of the residents asked every patient with $\mathrm{CHC}$ about alcohol use, while the rest asked patients most of the time or often.

As shown in Table 5, the residents identified multiple difficulties in engaging patients in discussions regarding $\mathrm{CHC}$ treatment. More than half of the participants reported that patients do not see a need for treatment, and nearly two-thirds responded that the patients are only interested in discussing the main reason for their primary care visit. One-third of the residents felt that the patients became offended when they discussed their hepatitis status. Thirteen percent felt that they lacked the knowledge to conduct a lengthy discussion and instead deferred the discussion to specialists.

Table 2. Awareness That Patient Population Should Be Screened for Hepatitis C Viral Infection

\begin{tabular}{lll} 
& n & \% \\
\hline Individuals born 1945 - 1965 & 64 & 77.11 \\
IVDU & 76 & 91.57 \\
Individuals with unsafe sexual habits & 66 & 79.52 \\
HIV patients & 75 & 90.36 \\
All patients aged 15 - 65 years & 36 & 43.37
\end{tabular}

Table 3. Awareness That Hepatitis C Is a Curable Disease

\begin{tabular}{lll}
\hline & n & \% \\
\hline Curable & 66 & 79.52 \\
Curable in certain conditions & 15 & 18.07 \\
Not curable & 2 & 2.41 \\
Do not know & 0 & 0.00 \\
\hline
\end{tabular}

Nearly $75 \%$ thought that their patients have a poor understanding of the disease progression, and a similar number of residents attributed this lack of knowledge to a lack of symptoms in the initial phase of the disease. Two-thirds of the residents viewed the need for multiple visits for evaluation as a barrier to treatment. Half of the residents stated that lack of insurance coverage contributed to the low rates of treatment as well as the fact that their patients did not feel that they needed to be treated. One-third of the residents believed that their patients are afraid of side effects, and a similar number viewed psychological illness as an additional barrier to treatment.

From their practice, two-thirds of the residents reported that the patients are not aware that cures are available and still believe that interferon is being used (Fig. 1). More than half of the residents spent 2 to $7 \mathrm{~min}$ counseling their patients about CHC and the available treatment options, while $27 \%$ reported spending more than $7 \mathrm{~min}$ in counseling.

Emphasis on duration of treatment and outcomes was the most important factor to increase the patient's linkage to care in the opinion of $92 \%$ of the participants. Eighty-eight percent and $83 \%$ thought that proper patient education about the disease and support groups, respectively, would be helpful.

Several barriers to treatment from the patient prospective are shown in Table 6 , and the factors that influence whether or not a referral is given from the resident perspective are given in Table 7.

\section{Discussion}

Chronic HCV infection is the most common cause of cirrhosis, HCC, liver transplantation in the United States [10]. Unfortunately, only a minority of $\mathrm{HCV}$-infected individuals receive treatment as a result of several barriers to care. Therefore, it is pivotal to assess the knowledge and insights of healthcare providers to bridge these deficiencies in care. Our study provides insight into $\mathrm{CHC}$ management and its challenges from

Table 4. Comorbidities in Hepatitis C Should Prompt Treatment

\begin{tabular}{lll} 
& n & \% \\
\hline Chronic kidney disease & 50 & 60.24 \\
Liver cirrhosis & 54 & 65.06 \\
Depression & 55 & 66.27 \\
Human immunodeficiency virus & 67 & 80.72 \\
Decompensated cirrhosis & 32 & 38.55 \\
\hline
\end{tabular}


Table 5. Difficulty in Engaging Patients for Treatment

\begin{tabular}{lll}
\hline & n & \% \\
\hline Interested in treatment for the main reason only & 50 & 60.24 \\
Do not see the need & 44 & 53.01 \\
Offended by discussion & 27 & 32.53 \\
Physician feeling deficient in knowledge & 11 & 13.25 \\
Lack of insurance & 47 & 56.63 \\
Prior authorization & 49 & 59.04 \\
\hline
\end{tabular}

the perspective of resident physicians in training.

Resident physicians play an important role in health care delivery in the US and spend a significant time of their training in outpatient settings. In our study, the majority of the residents reported encountering between 10 and 50 hepatitis $\mathrm{C}$ patients in the last year. However, there was some uncertainty amongst the residents regarding the population that needed to be screened for hepatitis C, including individuals born between 1945 and 1965 and intravenous drug users (IVDU). This is particularly important since Shalmaniv et al showed that IVDU is the most common route of HCV infection in the US [10].

A study conducted by Falade-Nwulia et al showed that a majority of primary care physicians (PCPs) $(89 \%)$ referred $\mathrm{HCV}$-infected patients to subspecialty clinics [11]. Market surveys in the US by Shiffman et al reported that $80 \%$ of HCV patients are managed by $20 \%$ of gastroenterologists [12]. Dubin et al, however, showed that specialist referrals of diagnosed $\mathrm{HCV}$ patients had failed to surpass $50 \%$ in several cross-sectional studies [13]. In our study, referrals to specialists were common; however, residents had varying opinions regarding the reasons for these referrals.

Falade-Nwulia et al reported that the majority of PCPs (77\%) were aware of the availability of new oral direct-acting agents, and more than two-thirds of them (67\%) had correctly identified $\mathrm{HCV}$ genotype as an important part of the $\mathrm{HCV}$
Table 6. Barrier to Treatment

\begin{tabular}{lll}
\hline & $\mathbf{n}$ & $\mathbf{\%}$ \\
\hline Poor understanding of the disease progression & 62 & 74.70 \\
Insurance unavailability & 45 & 54.22 \\
Lack of symptoms & 63 & 75.90 \\
The need for multiple visits & 52 & 62.65 \\
Does not see a need & 37 & 44.58 \\
Afraid of the side effect & 24 & 28.92 \\
Investigations take a lot of time & 16 & 19.28 \\
Mental health issues & 29 & 34.94 \\
\hline
\end{tabular}

treatment decision [11]. However, a significant proportion of residents were unaware of the available treatments for $\mathrm{CHC}$ in the setting of varies comorbidities. This was true despite that more than two-thirds of them felt like they had either fair or excellent knowledge of current recommendations. There are recommendations from a number of international societies for $\mathrm{HCV}$ infections including the American Association for the Study of Liver Disease (AASLD), the European Association for the Study of Liver (EASL), and the Asian Pacific Association for the Study of Liver (APASL) with promising treatment outcomes in HCV patients with several comorbidities.

Other prior surveys have shown that patient-level factors are viewed as the greatest obstacles to treatment [14-16]. This is consistent with our study, where nearly three quarters of the residents felt that the patients did not know the fate of untreated hepatitis $\mathrm{C}$, and one-third of the participants felt that the patients were not even aware that it could be cured. In fact, the majority of the residents thought that their patients were not aware of the newer treatments. Poordad et al reported that patient-level barriers also included concerns regarding treatment duration and antiviral effectiveness [17]. This is significant given that previous treatment with pegylated interferon

\section{PATIENTS' AWARENESS OF NEWER TREATMENTS}

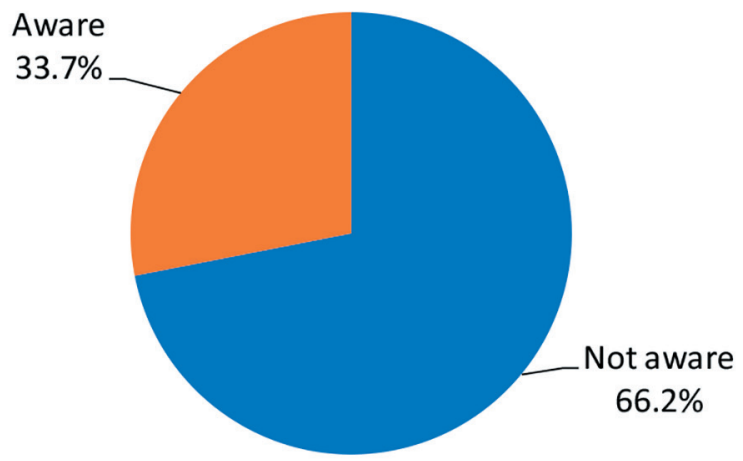

Figure 1. Patients' awareness of newer treatments. 
Table 7. Factors Influencing Referral

\begin{tabular}{lll} 
& n & \% \\
\hline Availability of specialty clinic & 70 & 84.34 \\
Time constraints & 6 & 7.23 \\
Insufficient training & 7 & 8.43 \\
\hline
\end{tabular}

plus ribavirin removed the virus in $54-56 \%$ of all treated patients, as measured at a 6-month follow-up [18-20], compared with current direct acting antivirals (DAAs) therapy, which is effective in more than $95 \%$ of patients after only 12 weeks of therapy. Furthermore, fear of treatment-related side effects was the most frequently cited barrier to initiating therapy in our study. This fear is not unfounded; nearly all patients will experience at least one treatment-related side effect, and nearly $10-14 \%$ of patients will discontinue treatment as a result [17]. Though side effects are common, appropriate pretreatment counseling along with a structured plan for monitoring and management may help alleviate such fears and help with compliance [21].

Some other perceived barriers in our study included patients' unwillingness to discuss $\mathrm{HCV}$ treatment, where the main reasons for the PCP visit, lack of insurance, and need for prior authorization of medications are discussed instead.

Previous studies of healthcare providers by Zickmund et al have demonstrated significant knowledge gaps related to $\mathrm{HCV}$; therefore, inadequate physician knowledge is a known barrier to care [22-24].

From the perspective of the residents, several steps like proper patient education and emphasizing the shorter duration and excellent outcomes of newer treatments can be carried out to engage patients in treatment.

Ultimately, patient and provider education, increased awareness, and treatment promotion are necessary if progress is to be made in the global fight against HCV infection [24].

\section{Conclusion}

Internal medicine residents in training are at the forefront of CHC patient care, and assessing their knowledge, attitudes, and practices will improve understanding and mitigate the different challenges associated with $\mathrm{CHC}$ treatment. Future guidelines and policies should involve these residents in training - a population that represents a skilled workforce of more than 26,000 physicians - in the battle against HCV.

\section{Financial Disclosures}

None of the authors have any financial disclosures.

\section{References}

1. Institute of Medicine Committee on the, P. and I. Control of viral hepatitis, in hepatitis and liver cancer: a national strategy for prevention and control of hepatitis B and C. Colvin HM, Mitchell AE, Editors. 2010, National Academies Press (US). Copyright 2010 by the National Academy of Sciences. All rights reserved.: Washington (DC).

2. Armstrong GL, Wasley A, Simard EP, McQuillan GM, Kuhnert WL, Alter MJ. The prevalence of hepatitis C virus infection in the United States, 1999 through 2002. Ann Intern Med. 2006;144(10):705-714.

3. Holmberg SD, Spradling PR, Moorman AC, Denniston MM. Hepatitis C in the United States. N Engl J Med. 2013;368(20):1859-1861.

4. Feld JJ, Jacobson IM, Hezode C, Asselah T, Ruane PJ, Gruener N, Abergel A, et al. Sofosbuvir and velpatasvir for hev genotype 1, 2, 4, 5, and 6 infection. N Engl J Med. 2015;373(27):2599-2607.

5. Khokhar OS, Lewis JH. Reasons why patients infected with chronic hepatitis $\mathrm{C}$ virus choose to defer treatment: do they alter their decision with time? Dig Dis Sci. 2007;52(5):1168-1176.

6. Morrill JA, Shrestha M, Grant RW. Barriers to the treatment of hepatitis C. Patient, provider, and system factors. J Gen Intern Med. 2005;20(8):754-758.

7. McGowan CE, Fried MW. Barriers to hepatitis C treatment. Liver international. 2012;32(01):151-156.

8. Medicine A.B.O.I.; Available from: http://www.abim. org/about/statistics-data/resident-fellow-workforce-data/ number-of-programs-residents.aspx.

9. https://www.acgme.org/Portals/0/PFAssets/ProgramRequirements/140_internal_medicine_2017-07-01.pdf.

10. Shalmani HM, Ranjbar $\bar{M}$, Alizadeh AHM. Recommendations for prevention and control of hepatitis $\mathrm{C}$ virus (HCV) infection and HCV-related chronic disease. J Liver. 2013;3(147):2167-0889.

11. Falade-Nwulia O, McAdams-Mahmoud A, Irvin R, Niculescu A, Page KR, Mix M, Thomas DL, et al. Primary care providers knowledge, attitude and practices related to hepatitis $\mathrm{C}$ screening and treatment in the oral direct acting antiviral agents era. J Community Med Health Educ. 2016;6(5):481.

12. Shiffman ML. A balancing view: We cannot do it alone. Am J Gastroenterol. 2007;102(9):1841-1843.

13. Dubin PH, Glaser FB. Knowledge gaps about hepatitis $\mathrm{c}$ prognosis and treatment among non-gastroenterologists and medical students. Pract Gastroenterol. 2015; XXXIX(1):49.

14. Fraenkel L, McGraw S, Wongcharatrawee S, GarciaTsao G. What do patients consider when making decisions about treatment for hepatitis C? Am J Med. 2005;118(12):1387-1391.

15. Evon DM, Simpson KM, Esserman D, Verma A, Smith S, Fried MW. Barriers to accessing care in patients with chronic hepatitis C: the impact of depression. Aliment Pharmacol Ther. 2010;32(9):1163-1173.

16. Parkes J, Roderick P, Bennett-Lloyd B, Rosenberg W. Variation in hepatitis $C$ services may lead to inequity of heath-care provision: a survey of the organisation and delivery of services in the United Kingdom. BMC Public Health. 2006;6:3.

17. Poordad F, McCone J, Jr., Bacon BR, Bruno S, Manns MP, 
Sulkowski MS, Jacobson IM, et al. Boceprevir for untreated chronic HCV genotype 1 infection. N Engl J Med. 2011;364(13):1195-1206.

18. Alter MJ, Seeff LB, Bacon BR, Thomas DL, Rigsby MO, Di Bisceglie AM. Testing for hepatitis $C$ virus infection should be routine for persons at increased risk for infection. Ann Intern Med. 2004;141(9):715-717.

19. Fried MW, Shiffman ML, Reddy KR, Smith C, Marinos G, Goncales FL, Jr., Haussinger D, et al. Peginterferon alfa-2a plus ribavirin for chronic hepatitis $\mathrm{C}$ virus infection. N Engl J Med. 2002;347(13):975-982.

20. Manns MP, McHutchison JG, Gordon SC, Rustgi VK, Shiffman M, Reindollar R, Goodman ZD, et al. Peginterferon alfa-2b plus ribavirin compared with interferon alfa$2 \mathrm{~b}$ plus ribavirin for initial treatment of chronic hepatitis C: a randomised trial. Lancet. 2001;358(9286):958-965.

21. Di Bisceglie AM, Shiffman ML, Everson GT, Lindsay
KL, Everhart JE, Wright EC, Lee WM, et al. Prolonged therapy of advanced chronic hepatitis $\mathrm{C}$ with low-dose peginterferon. N Engl J Med. 2008;359(23):2429-2441.

22. Zickmund SL, Brown KE, Bielefeldt K. A systematic review of provider knowledge of hepatitis $\mathrm{C}$ : is it enough for a complex disease? Dig Dis Sci. 2007;52(10):25502556.

23. Zickmund S, Hillis SL, Barnett MJ, Ippolito L, LaBrecque DR. Hepatitis C virus-infected patients report communication problems with physicians. Hepatology. 2004;39(4):999-1007.

24. Abad N, Malik T, Ariyarajah A, Ongpin P, Hogben M, McDonald SLR, Marrinan J, et al. Development of risk reduction behavioral counseling for Ebola virus disease survivors enrolled in the Sierra Leone Ebola Virus Persistence Study, 2015-2016. PLoS Negl Trop Dis. 2017;11(9):e0005827. 